\title{
Supply Chain Efficiency Analysis: A Theoretical Approach
}

Ming-Chung Chang, Kainan University, Taiwan Yung-Ho Chiu, Soochow University, Taiwan

\begin{abstract}
We divide the supply chain into a central control system (CCS) case and a decentralized control system (DCS) case, and compare the supply chain efficiency with both the CCS case and the DCS case. We find that the supply chain efficiency of a capital-intensive industry is better under the CCS case than under the DCS case. Under the CCS case, the maximized supply chain efficiency can be reached by choosing either the lowest price that the upstream firm is willing to receive or the highest price that the downstream firm is willing to pay for intermediate goods.
\end{abstract}

Keywords: Supply chain efficiency, DEA game, Bargaining process

\section{INTRODUCTION}

Q e introduce this section by considering the following subheadings.

Research Aim Data Envelopment Analysis (DEA) is a popular approach developed by Charnes et al. (1978) to study the relative performance of peer decision making units (DMUs) in practice. The application of the DEA model has been extended by Banker (1990), Weber and Desai (1996), Easton et al. (2002), Zhu (2003), Liang et al. (2006), Mu and Du (2006), Reiner and Hofmann (2006) and others to measure the relative efficiency of supply chain members. The objective of this paper is to measure the relative efficiency of different types of supply chain. While our research is similar to that of Chen et al. (2006), it also differs from theirs in that their objective function is based on the ratio of outputs and inputs, whereas ours is based on a maximized profit function or a minimized cost function. The objective function adopted in our paper fully reveals the spirit of game theory. Another advantage of our model is that it can be used to discuss supply chain efficiency under different degrees of capital intensity. Finally, Semple (1996) points out that many studies which have connected game theory to the evaluation of DEA efficiency have been found to have limited usefulness in practice. Hence we try to apply game theory to discuss a practical issue regarding the evaluation of supply chain efficiency.

Research Motivation It is well known that the costs of intermediate goods has a direct impact on the prices of final goods. Hence, the decision regarding the intermediate goods price has started to gain attention in the literature. In practice, over half of the profit is eroded by the intermediate goods cost. In order to increase the profitability of a supply chain, an appropriate supply chain management model has been examined by analyzing the external market and a negotiating contract (Cox, 1996). In an appropriate supply chain management model, the purchasers and the suppliers of the intermediate goods should communicate in an effort to decrease redundancies and increase the efficiency of the supply chain (Wisner and Tan, 2000). In our paper, we establish a micro-foundation to find an appropriate supply chain management model.

Previous Research The first study that connected game theory to DEA efficiency estimation was that introduced by Banker (1990). His paper, which was basically related to the BCC version of the DEA model, was established by Banker et al. (1984) and was concerned with many kinds of unconstrained two-person zero-sum games. Rousseau and Semple (1995) had a significant breakthrough in this field in that they constructed a new class of constrained two-person zero-sum games which was referred to as the Two-Person Ratio Efficiency Game (TPREG). The 
TPREG model connects game theory to the original CCR version of the DEA model which was introduced by Charnes et al. (1978). Semple (1996) further extended the TPREG model to the Constrained (Two-Person) Ratio Efficiency Game by including a polyhedron cone constraint in the pure strategies. Beamon (1998) paid attention to the performance and design of the supply chain. The contribution of this paper is that it provides a viewpoint regarding multi-stage supply chain modeling and also defines a research agenda for future research in this area. Kwak et al. (2006) analyzed the bargaining process in a supply chain, and developed two different supply chain models: one where the supplier has superior bargaining power over the buyer, and the other where the reverse case is true. Nagarajan and Sosic (2008) surveyed the applications of cooperative game theory in supply chain management by using the cooperative bargaining game to allocate the profit between the supply chain members.

DEA is a linear programming model that converts a single output and input variable or multiple output and input variables into a single index for estimating productivity efficiency (Epstein and Henderson, 1989). The primary advantage of DEA is that it provides a composite index for an efficiency measurement, thus enabling a more valid comparison of supply chain efficiency. DEA was originally utilized in non-profit fields such as in hospital efficiency measurement (Sherman, 1986), national park efficiency estimation (Rhodes, 1986), and non-profit organizations (Ahn et al. 1989). However, DEA has been extended to the for-profit sector and private institutes. More specifically, Weber and Desai (1996) used DEA to set up an index for evaluating a supplier's relative performance. Lothgren and Tambour (1999) employed a DEA-based network model and used Swedish pharmacies as an example to study the behavior of both producers and consumers. Easton et al. (2002) employed a DEA model to compare a firm's purchasing efficiency in the petroleum industry. Zhu (2003) used a DEA-based model to investigate multiple members' supply chain efficiency. Castelli et al. (2004) utilized a DEA-based model to evaluate the DMU efficiency of a two-level hierarchical structure. Chen et al. (2006) used the original DEA definition to compare two kinds of supply chain efficiency, one being a centralized control system (CCS) type of supply chain, and the other supply chain a decentralized control system (DCS) type. Liang et al. (2006) used the DEA approach to characterize and measure the efficiency of different supply chain types when the purchase of intermediate goods was incorporated into the supply chain performance evaluation. The first supply chain type that they treated in their paper was a leader-follower relationship between the seller and buyer, and the second one was a cooperative relationship. They asserted that in the leader-follower structure, the leader was first evaluated, and then the follower was evaluated using the information that is revealed by the leader's efficiency. In the cooperative structure, the supply chain members are evaluated simultaneously by maximizing the joint efficiency that is modeled as the average efficiency scores of the seller and the buyer. $\mathrm{Mu}$ and $\mathrm{Du}$ (2006) used the DEA model to estimate the efficiency of different supply chain integration projects. The supply chain integration project that was based on both orderly and synthetic approaches considered both forward and reverse logistics. Reiner and Hofmann (2006) combined dependency analysis and DEA to analyze supply chain performance. They first used dependency analysis to determine the input and output variables, and then used the DEA approach to measure the supply chain performance. Their model found evidence of a potential improvement in the estimation of basic supply chain efficiency.

Research Approach The concept of DEA efficiency analysis is equivalent to the best production strategy analysis that encourages a DMU to make progress when it competes with others. Besides, we also introduce game theory in order to reveal the additional insights into practical efficiency analysis. In this paper, we combine the concepts of DEA efficiency analysis and game theory in an empirical analysis.

Originality of the Paper and Contribution We find that the supply chain efficiency of a capital-intensive industry is better under the CCS case than under the DCS case. Under the CCS case, the maximized supply chain efficiency can be reached by choosing either the lowest intermediate goods price that the upstream firm is willing to receive or the highest intermediate goods price that the downstream firm is willing to pay.

The rest of this paper is organized as follows. Section 2 provides the theoretical framework for this paper. Section 3 presents the methodology used in the paper. Section 4 introduces the model set-up of a DEA-based supply chain efficiency game with two members. Section 5 discusses supply chain efficiency under CCS and DCS, and provides a numerical example. Section 6 concludes the paper. 


\section{THEORETICAL FRAMEWORK}

In this paper, we combine game theory with the DEA approach in discussing the different types supply chain efficiency. There are two kinds of supply chain types discussed in this paper, namely, CCS and DCS. The supply chain components in our paper comprise an intermediate goods supplier (upstream firm) and a producer (downstream firm). Since there is only one manager in the CCS supply chain to coordinate the operation of the whole supply chain, the competitive relationship between the supplier and the producer in the CCS supply chain is cooperative. However, in the DCS supply chain, the supplier and the producer manage the whole supply chain by means of a common governance. Hence, the relationship between the supplier and the producer in the DCS supply chain is competitive. Since the CCS supply chain and the DCS supply chain have different competitive modes, we use game theory to describe the different competitive relationships for the different supply chain types.

We view the whole supply chain as a DMU, and hence the relationship between the inputs and the outputs decides the performance of the DMU. DEA is a linear programming model that converts input and output variables into a single index in order to estimate productivity efficiency. We employ the DEA approach to compare the supply chain efficiency since it provides a single index for an efficiency measurement. The theoretical framework of our paper is illustrated in Graph 1.

Graph 1: Theoretical framework of the model

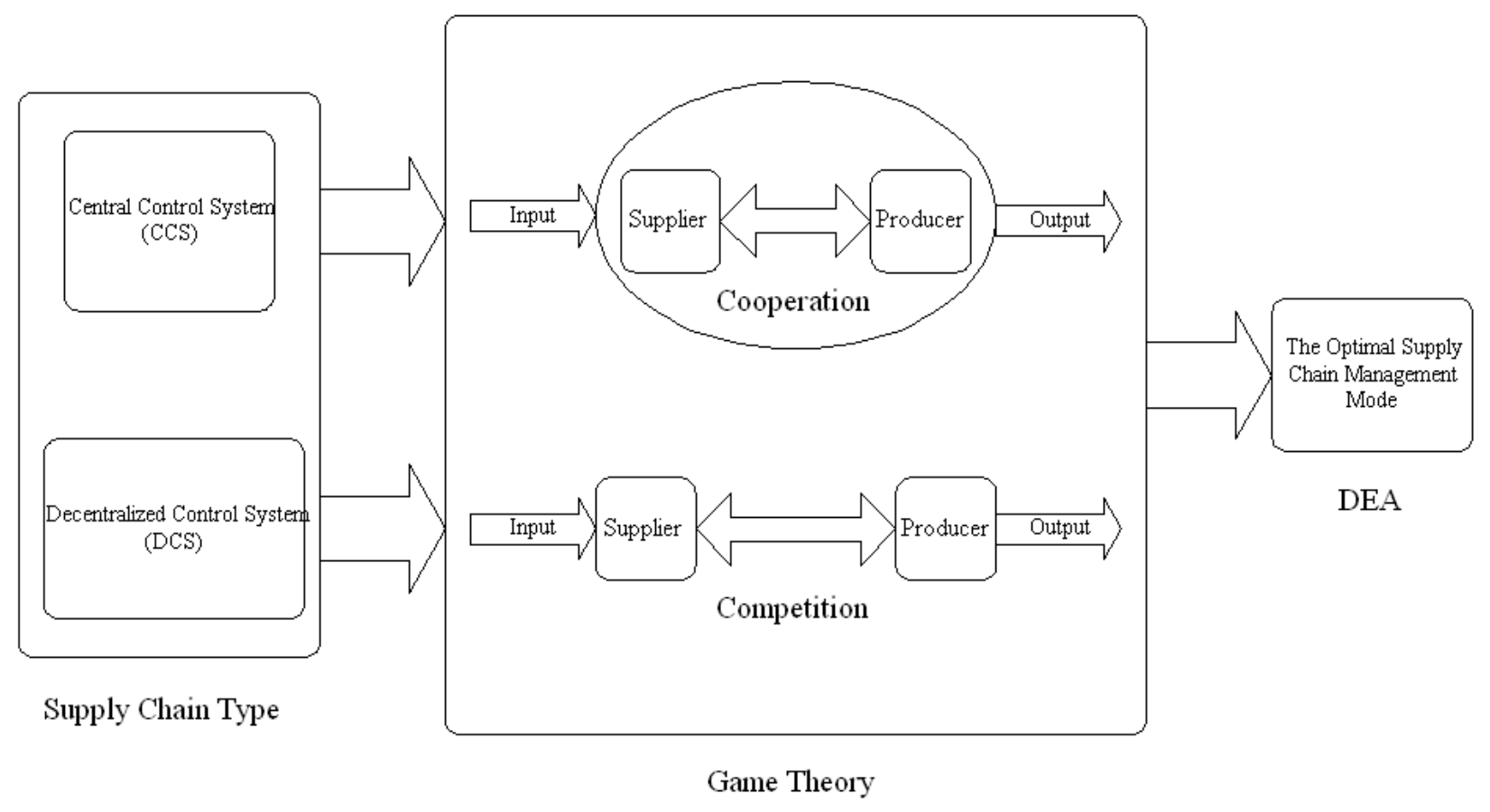

\section{METHODOLOGY}

According to the theoretical framework of the model depicted in Graph 1, the theoretical sources of our model are game theory and the DEA approach. In addition, based on the micro-foundation of economics, the supplier and the producer in the CCS supply chain decide an intermediate goods price by maximizing the joint profit. However, in the DCS supply chain, the intermediate goods price is decided by maximizing the individual profits of the supplier and the producer. Since the different supply chain types decide the different intermediate goods prices, the inputs and the outputs within the supply chain are impacted differently. At the same time, the supply chain 
efficiency is also impacted. Hence, we try to estimate the supply chain efficiency under the different kinds of supply chain. Another primary advantage of our model is that we can estimate the supply chain efficiency under different degrees of capital intensity.

Based on the basic concept of DEA, we view the profit of the supply chain as an output variable and the production cost of the supply chain as an input variable in estimating the supply chain efficiency. Since the intermediate goods price may be different for the different kinds of supply chain, and the intermediate goods price also impacts the inputs (production cost) and the output (profit) of the supply chain, we can infer that the different supply chain types may also have different efficiency values.

\section{MODEL SET-UP}

Consider a supply chain composed of one upstream firm $(U)$ and one downstream firm $(D)$. The downstream firm buys the input factor $\left(Y_{U}\right)$ from the upstream firm and additionally uses another input factor $(H)$ to transform them into the final product $\left(Y_{D}\right)$. We assume that the production function of a downstream firm is of the Cobb-Douglas form as $Y_{D}=B H^{\beta} Y_{U}^{1-\beta}$, where $\beta \in(0,1)$ represents the degree of factor intensity for the downstream firm. For the downstream firm, the input factor prices for $H$ and $Y_{U}$ are $m$ and $w_{B}$, respectively. We assume that the cost function of the downstream firm has a linear form as $C_{D}=m H+w_{B} Y_{U}$. The upstream firm has two input factors $L$ and $K$, and their prices are $w$ and $r$, respectively. We assume that the production function of the upstream firm is also of the Cobb-Douglas form as $Y_{U}=A L^{\alpha} K^{1-\alpha}$, where $\alpha \in(0,1)$ represents the degree of factor intensity for the upstream firm. The upstream firm also has a linear cost function as $C_{U}=w L+r K$.

A conflict exists between the upstream firm and downstream firm with respect to the intermediate good $Y_{U}$. If $w_{B} Y_{U}$ represents the upstream firm's profit, then the upstream firm wishes to maximize it while the downstream firm wishes to minimize it as it represents a cost to the downstream firm. In other words, the upstream firm and downstream firm compete in terms of the intermediate good price $w_{B}$. Each firm chooses the optimal amount of input in order to minimize cost subject to the specified output level. The upstream firm's minimized cost problem is formulated as follows:

$\underset{L, K}{\operatorname{Min}} C_{U}=w L+r K$

subject to $Y_{U 0}=A L^{\alpha} K^{1-\alpha}$,

where $Y_{U 0}$ is a specified output level.

Similarly, the downstream firm's minimized cost problem is formulated as follows:

$\underset{H}{\operatorname{Min}} C_{D}=m H+w_{B} Y_{U}$

subject to $Y_{D 0}=B H^{\beta} Y_{U}^{1-\beta}$,

where $Y_{D 0}$ is a specified output level.

From Equation (1), the optimal amounts of the input factors for the upstream firm are:

$L^{*}=\frac{Y_{U 0}}{A\left(\frac{r}{w} \frac{1-\alpha}{\alpha}\right)^{1-\alpha}}$, and $K^{*}=\frac{Y_{U 0}}{A\left(\frac{r}{w} \frac{1-\alpha}{\alpha}\right)^{-\alpha}}$.

From Equation (2), the optimal amounts of the input factors for the downstream firm are: 
$H^{*}=\frac{Y_{D 0}}{B\left(\frac{m}{w_{B}} \frac{1-\beta}{\beta}\right)^{1-\beta}}$.

Based on the concept of efficiency in Charnes et al. (1978), the efficiency for the upstream firm and the downstream firm are respectively defined as:

$$
\begin{aligned}
& \lambda_{U}=\frac{w_{B} Y_{U 0}}{w L^{*}+r K^{*}}, \\
& \lambda_{D}=\frac{P Y_{D 0}}{w_{B} Y_{U 0}+m H^{*}},
\end{aligned}
$$

where $P$ is the market price of final goods.

From the above two equations, the maximized value of $\lambda_{U}$ is $w_{B} \rightarrow \infty$. Similarly, the maximized value of $\lambda_{D}$ is $w_{B} \rightarrow 0$.

Given the upstream firm's and downstream firm's efficiency levels as asked by them, i.e., $\lambda_{U} \geq \lambda_{U}{ }^{-}$and $\lambda_{D} \geq \lambda_{D}{ }^{-}$, we obtain the price interval that the upstream firm wants to charge as $w_{B}^{U} \in\left[\lambda_{U}^{-}\left(w L^{*}+r K^{*}\right) / Y_{U 0}, \infty\right)$. Similarly, the price that the downstream firm wants to charge $w_{B}{ }^{D}$ has to satisfy the following equation:

$a_{1} w_{B}^{D}+b_{1}\left(w_{B}^{D}\right)^{1-\beta}+c_{1} \leq 0$,

where $a_{1}=\lambda_{D}{ }^{-} Y_{U 0} B\left(\frac{m(1-\beta)}{\beta}\right)^{1-\beta}>0, b_{1}=\lambda_{D}{ }^{-} m Y_{D 0}>0$, and $c_{1}=-P Y_{D 0} B\left(\frac{m(1-\beta)}{\beta}\right)^{1-\beta}<0$.

Because the upstream firm asks that the lowest efficiency level be $\lambda_{U}^{-}$, the upstream firm must ask that the lowest intermediate goods price be $w_{B}{ }^{U L}=\left[\lambda_{U}^{-}\left(w L^{*}+r K^{*}\right)\right] / Y_{U 0}$. On the other hand, the downstream firm's maximized willingness to pay for intermediate goods is $w_{B}{ }^{D H}$ for maintaining its lowest efficiency level $\lambda_{D}{ }^{-}$, and $w_{B}{ }^{D H}$ has to satisfy Equation (7). If the game is feasible, then the reasonable relationship between $w_{B}{ }^{U L}$ and $w_{B}{ }^{D H}$ is $w_{B}^{U L} \leq w_{B}^{D H}$. On the contrary, if $w_{B}^{U L}>w_{B}^{D H}$, then the game is not feasible.

We next define the supply chain efficiency as follows:

$\lambda_{S}^{*}=\operatorname{Max}_{w_{B}}\left\{\lambda_{S}=\left(w_{B} Y_{U 0}+P Y_{D 0}\right) /\left(w L^{*}+r K^{*}+w_{B} Y_{U 0}+m H^{*}\left(w_{B}\right)\right): \quad \lambda_{U}>0, \lambda_{D}>0\right\}$.

The above definition shows that supply chain efficiency depends on the decision for the intermediate goods price. From the first-order condition, the intermediate goods price is $w_{B}{ }^{*} \cdot{ }_{1}$ However, $w_{B}{ }^{*}$ violates the second-order condition. Thus, the optimal intermediate goods price is a corner solution.

\section{CENTRAL CONTROL SYSTEM AND DECENTRALIZED CONTROL SYSTEM}

The CCS and DCS are two kinds of management modes in a supply chain. In this section we compare supply chain efficiency under two kinds of supply chain management modes.

\footnotetext{
${ }^{1}$ The intermediate goods $w_{B}{ }^{*}$ and $w_{B}{ }^{*}$ satisfy $a_{2} w_{B}{ }^{*}-b_{2}\left(w_{B}{ }^{*}\right)^{\beta}-c_{2}=0$, where $a_{2}=\frac{\beta m Y_{D D} Y_{U 0}}{B\left(m \frac{1-\beta}{\beta}\right)^{1-\beta}}>0, b_{2}=\left(P Y_{D 0}-w L^{*}-r K^{*}\right) Y_{U 0}$, and $c_{2}=\frac{m(1-\beta) P Y_{D 0}^{2}}{B\left(m \frac{1-\beta}{\beta}\right)^{1-\beta}}>0$.
} 


\subsection{CENTRAL CONTROL SYSTEM}

In a central control system (CCS), there is a single decision maker who assigns the upstream firm and the downstream firm efficiencies for maximizing supply chain efficiency. However, if the downstream firm cannot realize its own minimum acceptable efficiency level $\lambda_{D}{ }^{-}$, then it will not agree to set up a supply chain with the upstream firm. Similarly, if the upstream firm cannot realize its own minimum acceptable efficiency level $\lambda_{U^{-}}$, then it will also not agree to set up a supply chain with the downstream firm. Thus the central manager chooses the optimal intermediate price to maximize supply chain efficiency, and to satisfy the upstream firm's and downstream firm's efficiency values as asked by themselves. Thus, according to Equation (8) the optimal supply chain efficiency can be expressed as:

$\lambda_{S C C S}{ }^{*}=\operatorname{Max}\left\{\lambda_{S}\left(w_{B}{ }^{U L}\right), \lambda_{S}\left(w_{B}{ }^{D H}\right): \quad \lambda_{U} \geq \lambda_{U}^{-}, \lambda_{D} \geq \lambda_{D}{ }^{-}\right.$, and $\left.w_{B}{ }^{U L} \leq w_{B}{ }^{D H}\right\}$.

Proposition: To maximize the supply chain efficiency in the CCS case, the central manager chooses either the upstream firm's lowest willingness to receive the price $\left(\mathrm{w}_{\mathrm{B}}^{\mathrm{UL}}\right)$ or the downstream firm's highest willingness to pay $\left(\mathrm{w}_{\mathrm{B}}{ }^{\mathrm{DH}}\right)$ as the intermediate goods price. This decision is based on the shape of the supply chain efficiency function with the CCS case (i.e., $\lambda \mathrm{s}$ ).

\subsection{DECENTRALIZED CONTROL SYSTEM}

In a decentralized control system (DCS), the upstream firm and the downstream firm control their own efficiency. In other words, both of them make efforts to maximize their own efficiency. Because the intermediate good is the upstream firm's profit and downstream firm's cost, the upstream firm or the downstream firm has to minimize the opponent's efficiency. Thus, a bargaining model is used to examine the efficiency conflict between the upstream firm and the downstream firm.

The bargaining process with infinite periods is as depicted by Figure 1. Shaked and Sutton (1984) showed that the solution for the bargaining process with infinite periods is the same as the solution for the sub-game bargaining process beginning with the third period. Thus, the bargaining process with infinite periods can be translated into a bargaining process with three periods as shown in Figure 2.

\section{Graph 1: A bargaining process with infinite periods}

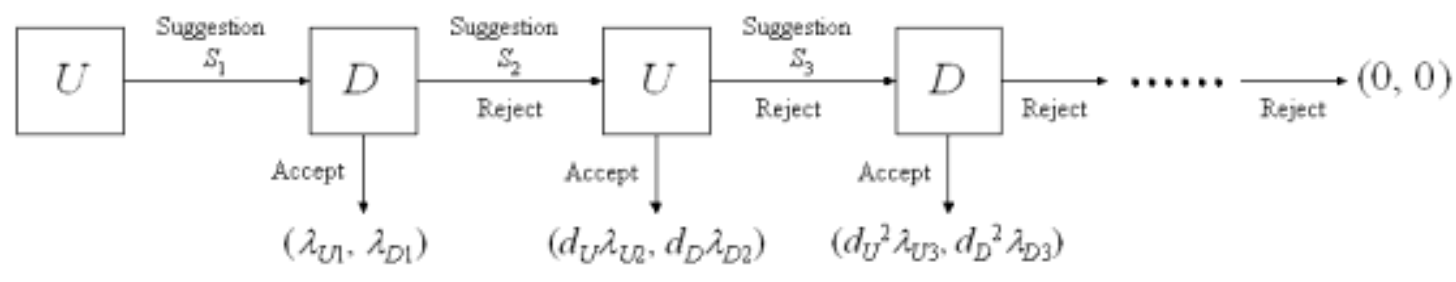

Graph 2: A bargaining process with three periods

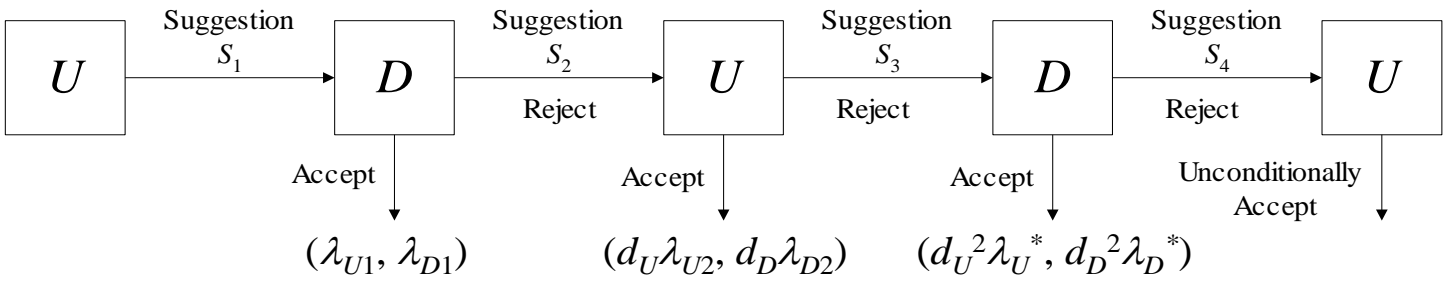

\begin{tabular}{l|l|l} 
The First Period & The Second Period & The Third Period
\end{tabular} 
Based on Shaked and Sutton (1984), if the upstream firm's suggestion $\left(S_{3}\right)$ in the second period cannot be accepted by the downstream firm, then it will accept any suggestion provided by the downstream firm in the third period unconditionally. Consider a bargaining game with three periods as shown in Figure 2. The bargaining process begins with suggestion $1\left(S_{1}\right)$ provided by the upstream firm $(U)$. The downstream firm $(D)$ makes a decision of either acceptance or rejection. If the downstream firm accepts $S_{1}$, then the game is over at the efficiency pair $\left(\lambda_{U 1}, \lambda_{D 1}\right)$. The former efficiency pair $\left(\lambda_{U 1}, \lambda_{D 1}\right)$ is the efficiency value of the upstream firm and the latter is the efficiency value of the downstream firm. If the downstream firm rejects $S_{1}$, then the downstream firm sets a new suggestion $2\left(S_{2}\right)$. The upstream firm makes a decision for either acceptance or rejection. The game does not end until one member of the supply chain accepts another member's suggestion.

Because the upstream firm and downstream firm incur some bargaining cost in the bargaining process, the time value is considered in this model. Assume the upstream firm's and the downstream firm's discount rates are $d_{U}$ and $d_{D}$, respectively, where $0<d_{U}<1$ and $0<d_{D}<1$. If the agreement happened in the $i$ th period with suggestion $\left(S_{i}\right)$, then the real efficiency pair for the upstream firm and downstream firm is $\left(d_{U}^{i-1} \lambda_{U i}, d_{D}{ }^{i-1} \lambda_{D i}\right)$. In a bargaining game with infinite periods, if $i \rightarrow \infty$, then $\left(d_{U}^{i-1} \lambda_{U i}, d_{D}{ }^{i-1} \lambda_{D i}\right) \rightarrow(0,0)$.

Assume that the optimal solution for the bargaining game with three periods in the third period is $\left(\lambda_{U}{ }^{*}, \lambda_{D}{ }^{*}\right)$. According to Shaked and Sutton (1984), the upstream firm has to unconditionally accept any suggestion from the downstream firm during the third period. It is thus ideal for the upstream firm to accept suggestion $2\left(S_{2}\right)$ provided by the downstream firm. However, suggestion $2\left(S_{2}\right)$ should satisfy $d_{U} \lambda_{U 2}=d_{U}{ }^{2} \lambda_{U}{ }^{*}$ and $\lambda_{D}{ }^{*}=d_{D} \lambda_{D 2}$. It can be said that if $\lambda_{U 2}=d_{U} \lambda_{U}{ }^{*}$ and $\lambda_{D}{ }^{*}=d_{D} \lambda_{D 2}$, then $\left(\lambda_{U}{ }^{*}, \lambda_{D}{ }^{*}\right)$ is a sub-game perfect Nash equilibrium and satisfies (i) $\lambda_{D}{ }^{*}$ $=E_{D}\left(\lambda_{U}{ }^{*}\right)$; (ii) $\lambda_{D 2}=E_{D}\left(\lambda_{U 2}\right)$, i.e., $\left(1 / d_{D}\right) \lambda_{D}{ }^{*}=E_{D}\left(d_{U} \lambda_{U}{ }^{*}\right){ }^{2} \quad$ Using the Nash equilibrium condition to estimate the optimal intermediate good price for the DCS case $\left(w_{B}{ }^{D C S}\right)$ means that $w_{B}{ }^{D C S}$ has to satisfy the following equation:

$a_{3}\left(w_{B}{ }^{D C S}\right)^{2}+b_{3}\left(w_{B}{ }^{D C S}\right)^{2-\beta}-c_{3}=0$, where

$a_{3}=1, b_{3}=\left(\frac{m^{\beta} Y_{D 0}}{B Y_{U 0}}\right)\left(\frac{1-\beta}{\beta}\right)^{1-\beta}>0, c_{3}=\frac{P Y_{D 0}\left(w L^{*}+r K^{*}\right)}{d_{D} d_{U} Y_{U 0}{ }^{2}}>0$.

Thus, the supply chain efficiency under the decentralized control system (DCS) case can be summarized as:

$\lambda_{S D C S}{ }^{*}=\lambda_{S}\left(w_{B}{ }^{D C S}\right)$.

\subsection{NUMERICAL EXAMPLE}

Suppose there are 9 types of downstream firm, i.e., $\beta=0.1,0.2, \ldots, 0.9$. The production functions of the upstream firm and downstream firm are $Y_{U}=L^{0.2} K^{0.8}$ and $Y_{D}=3 H^{\beta} Y_{U}{ }^{1-\beta}$, respectively. Obviously, the upstream firm is a capital-intensive firm such as a bank. However, the factor intensity of the downstream firm is not necessary. If $\beta$ is low, then there is a close relationship between the upstream firm and the downstream firm like that for a bank and an insurance corporation under the same financial holding company. On the contrary, if $\beta$ is high, then there is a distant relationship between them. The relationship is like that between an independent bank and an independent insurance company that are connected by a cooperative contract. We also assume that the

\footnotetext{
2 The upstream firm accepts suggestion $2\left(S_{2}\right)$ provided by the downstream firm and the efficiency values for the upstream firm and downstream firm are $d_{U} \lambda_{U 2}$ and $d_{D} \lambda_{U 2}$, respectively. Because suggestion $2\left(S_{2}\right)$ is provided by the downstream firm, the efficiency value of the downstream firm has to satisfy $d_{D} \lambda_{D 2}=\lambda_{D}{ }^{*}$. If suggestion $2\left(S_{2}\right)$ is accepted by the upstream firm, then the efficiency values of the upstream firm should be indifferent between suggestion $2\left(S_{2}\right)$ and suggestion $3\left(S_{3}\right)$, i.e., $d_{U} \lambda_{U 2}=$ $d_{U} \lambda_{U}{ }^{*}$. By $d_{D} \lambda_{D 2}=\lambda_{D}{ }^{*}$, we obtain $\lambda_{D 2}=\left(1 / d_{D}\right) \lambda_{D}{ }^{*}$, and $E_{D}\left(d_{U} \lambda_{U 2}\right)=E_{D}\left(d_{U} \lambda_{U}{ }^{*}\right)=\lambda_{D 2}$. Thus, we obtain $\left(1 / d_{D}\right) \lambda_{D}{ }^{*}=E_{D}\left(d_{U} \lambda_{U}{ }^{*}\right)$. This implies that the downstream firm will seek a maximized conditional efficiency $E_{D}\left(d_{U} \lambda_{U}{ }^{*}\right)$ under the condition that the upstream firm's efficiency is equal to $d_{U} \lambda_{U}{ }^{*}$.
} 
factor prices of $L, K$, and $H$ are 1, i.e., $w=r=m=1$, and that the price of final goods is 10 , i.e., $P=10$. The outputs of the upstream firm and downstream firm are 10 and 100, respectively. When the upstream firm and downstream firm become a supply chain, the lowest efficiency values which are asked by the upstream firm and downstream firm are 5, i.e., $\lambda_{U}{ }^{-}=\lambda_{D}{ }^{-}=5$. Since both of them have the same time cost, we assume that $d_{U}$ and $d_{D}$ are equal to 0.5 . The numerical results are as follows:

Table 1: Supply Chain Efficiency Scores for the CCS and DCS Cases

\begin{tabular}{ccccc}
\hline \multirow{2}{*}{ Supply Chain Type } & \multicolumn{2}{c}{ CCS } & \multicolumn{2}{c}{ DCS } \\
\cline { 2 - 5 } & ${ }_{w_{B}{ }^{C C S}\left(=w_{B}{ }^{U L}=w_{B}{ }^{D H}\right)}$ & $\lambda_{S C C S}{ }^{*}$ & $w_{B}{ }^{D C S}$ & $\lambda_{S D C S}{ }^{*}$ \\
\hline$\beta=0.1$ & 8.247 & 8.341 & 22.202 & 3.896 \\
$\beta=0.2$ & 8.247 & 6.833 & 20.292 & 3.521 \\
$\beta=0.3$ & 8.247 & 6.026 & 19.378 & 3.344 \\
$\beta=0.4$ & 8.247 & 5.648 & None & None \\
$\beta=0.5$ & 8.247 & 5.560 & 19.376 & 3.344 \\
$\beta=0.6$ & 8.247 & 5.693 & 19.998 & 3.464 \\
$\beta=0.7$ & 8.247 & 6.017 & 20.888 & 3.637 \\
$\beta=0.8$ & 8.247 & 6.519 & None & None \\
$\beta=0.9$ & 8.247 & 7.205 & 23.001 & 4.055 \\
\hline
\end{tabular}

In Table 1, "None" means that the sub-game perfect Nash equilibrium does not exist. We summarize some of the findings from Table 1 by pointing out that the supply chain efficiency for the CCS case is superior to the supply chain efficiency for the DCS case. The price of intermediate goods for the CCS case is always lower than the price of intermediate goods for the DCS case. It is also shown that supply chain efficiency is always higher under the CCS case than under the DCS case. However, the price of intermediate goods from the bargaining process is always high and a high intermediate goods price creates low supply chain efficiency. The bargaining process sometimes does not have a sub-game perfect Nash equilibrium. On the contrary, it is of benefit to the capital-intensive industry to form a supply chain with CCS. Thus, many financial holding companies have been established in Taiwan.

\subsection{DISCUSSION}

In the above subsection, we provide a numerical example to explain a phenomenon in Taiwan that different financial institutions, such as banks, securities companies and insurance companies, merge with each other to become a financial supply chain, such as a financial holding company. In our numerical example, we let the upstream firm be a capital-intensive firm and the downstream firm be either a capital-intensive firm ( $\beta$ is small) or a non-capital-intensive firm ( $\beta$ is large). Since we focus on how the supply chain type and capital intensity influence the supply chain's efficiency, we let the other numerical settings in our example be equal. Hence, our numerical setting fits the model's assumptions and the research objectives.

Our analytic result shows that the capital intensity supply chain should adopt the CCS management model. It can be inferred from this conclusion that, under the merger policy, the banks, the securities companies and the insurance companies should form a financial holding company. The findings in this paper can explain the phenomenon of the financial market in Taiwan. Hence, our theoretical framework and numerical example are consistent with real phenomena.

\section{CONCLUDING REMARKS}

Past studies which connect game theory to the DEA-based efficiency model have been limited in their usefulness when estimating efficiency. The current study follows the basic definition of the CCR version of the 
DEA model in evaluating supply chain efficiency with two members under both a centralized control system and decentralized control system. More specifically, we discuss the impact on supply chain efficiency with respect to the difference in factor intensity. Because the upstream firm within a supply chain produces intermediate goods as the input of the downstream firm in another supply chain, they are in conflict with each other when it comes to measuring the price of the intermediate goods. In other words, the reason for the conflict is that the upstream firm seeks to maximize profit and the downstream firm seeks to minimize cost. It is shown that the optimal intermediate goods' price is decided by either the upstream firm or the downstream firm under a centralized control system. The intermediate goods' price under a centralized control system is lower than that under a decentralized control system. Supply chain efficiency under a centralized control system is higher than that under a decentralized control system. Finally, the central manager can maximize supply chain efficiency by choosing either the upstream firm's lowest degree of willingness to receive the price or the downstream firm's highest degree of willingness to pay the intermediate goods price.

\section{AUTHOR INFORMATION}

Ming-Chung Chang is Assistant Professor of Department of Risk Management at Kainan University, Taiwan. His research field focuses on enterprise risk management, environmental economics and international technology licensing. His study has been published in international journal including "Economic Modeling", "Applied Economics", "International Journal of Information Technology and Decision Making", "Polish Journal of Environmental Studies" and so on.

Yung-Ho Chiu is Professor of Department of Economics and Dean of Business School at Soochow University, Taiwan. His research field mainly focuses on industrial economics, efficiency and productivity analysis, and bank risk management. His study has been published in many international journal including "Economic Modeling", "Applied Economic Letter", "International Journal of Manpower", "Service Industries Journal" and so on.

\section{REFERENCES}

1. Ahn, T., Arnold, V., Charnes, A. \& Cooper, W.W., "DEA and Ratio Efficiency Analysis for Public Institutions of Higher Learning in Texas", Research in Governmental and Nonprofit Accounting, Vol. 5, pp. 165-185, 1989.

2. Banker, R.D., "A Game Theoretic Approach to Measuring Efficiency", European Journal of Operational Research, Vol. 5, pp. 262-268, 1990.

3. Banker, R.D., Charnes, A. \& Cooper, A.A., "Some Models for Estimating Technical and Scale Inefficiencies in Data Envelopment Analysis", Management Science, Vol. 30, pp. 1078-1092, 1984.

4. Beamon, M.B., "Supply Chain Design and Analysis: Models and Methods", International Journal of Production Economics, Vol. 55, pp. 281-294, 1998.

5. Castelli, L., Pesenti, R. \& Ukovich, W., "DEA-Like Models for the Efficiency Evaluation of Hierarchically Structured Units", European Journal of Operational Research, Vol. 154, pp. 465-476, 2004.

6. Charnes, A., Cooper, W.W. \& Rhodes, E., "Measuring the Efficiency of Decision Making Units", European Journal of Operational Research, Vol. 2, pp. 429-444, 1978.

7. Chen, Y., Liang, L. \& Yang, F, “A DEA Game Model Approach to Supply Chain Efficiency”, Annals of Operations Research, Vol. 145, pp. 5-13, 2006.

8. Cox, A., "Relational Competence and Strategic Procurement Management: towards an Entrepreneurial and Contractual Theory of the Firm", European Journal of Purchasing and Supply Management, Vol. 2, pp. 57-70, 1996.

9. $\quad$ Easton, L., Murphy, D.J. \& Pearson, J.N., "Purchasing Performance Evaluation: With Data Envelopment Analysis", European Journal of Purchasing \& Supply Management, Vol. 8, pp. 123-134, 2002.

10. Epstein, M.K. \& Henderson, J.C., "Data Envelopment Analysis for Managerial Control and Diagnosis", Decision Science, Vol. 20, pp. 90-119, 1989.

11. Liang, L., Yang, F., Cook, W. \& Zhu, J., "DEA Models for Supply Chain Efficiency Evaluation”, Annals of Operations Research, Vol. 145, pp. 35-49, 2006. 
12. Lothgren, M. \& Tambour, M., "Productivity and Customer Satisfaction in Swedish Pharmacies: A DEA Network Model”, European Journal of Operational Research, Vol. 115, pp. 449-458, 1999.

13. Kwak, T., Kim, J. and Moon, C., "Supplier-buyer Models for the Bargaining Process over a Long-term Replenishment Contract”, Computers and Industrial Engineering, Vol. 51, pp. 219-228, 2006.

14. Mu, D. \& Du, Z., "DEA Analysis of Reverse Logistics of Supply Chain Integration Project Choice", Journal of Systems Science and Information, Vol. 4, pp. 1-8, 2006.

15. Nagarajan, M. \& Sosic, G., "Game-theoretic Analysis of Cooperation among Supply Chain Agents: Review and Extensions”, European Journal of Operational Research, Vol. 187, pp. 719-745, 2008.

16. Reiner, G. \& Hofmann, P., "Efficiency Analysis of Supply Chain Processes”, International Journal of Production Research, Vol. 44, pp. 5065-5087, 2006.

17. Rhodes, E.L., "An Exploratory Analysis of Variations in Performance among US Parks”, Measuring Efficiency: an Assessment of Data Envelopment Analysis. New Directions for Program Evaluation. Jossey-Bass, San Francisco, 1986.

18. Rousseau, J.J. \& Semple, J.H., "Two-person Ratio Efficiency Games”, Management Science, Vol. 41, pp. 435-441, 1995.

19. Semple, J.H, “Constrained Games for Evaluating Organizational Performance”, European Journal of Operational Research, Vol. 96, pp. 103-112, 1996.

20. Shaked, A. \& Sutton, J., "Involuntary Unemployment as a Perfect Equilibrium in a Bargaining Model”, Econometrica, Vol. 52, pp. 1351-1364, 1984.

21. Sherman, H.D., "Managing Productivity of Health Care Organizations”, Measuring Efficiency: an Assessment of Data Envelopment Analysis. New Directions for Program Evaluation. Jossey-Bass, San Francisco, Winter, 1986.

22. Weber, C.A. \& Desai, A., "Determinants of Paths to Vendor Market Efficiency Using Parallel Coordinates Representation: A Negotiation Tool for Buyers", European Journal of Operational Research, Vol. 90, pp. 142-155, 1996.

23. Wisner, J.D. \& Tan, K.C., "Supply Chain Management and Its Impact on Purchasing”, Journal of Supply Chain Management, Vol. 36, pp. 33-42, 2000.

24. Zhu, J., Quantitative Models for Performance Evaluation and Benchmarking: Data Envelopment Analysis with Spreadsheets. Boston: Kluwer Academic Publishers, 2003. 